\title{
Glucosa-Insulin-Potassium (GIK) Solution Used with Diabetic Patients Provides Better Recovery After Coronary Bypass Operations
}

\author{
Slavenka Straus, Vjekoslav Gerc, Mirsad Kacila, Faruk Custovic \\ Heart Center, Clinical Center of University of Sarajevo, Bosnia and Herzegovina
}

\begin{abstract}
ntroduction: Tight blood glucose control has become a therapeutical goal for anesthetic management for patients scheduled for cardiac surgery, especially if they are diabetic patients. Aim: This study was created to confirm the benefits of intraoperative GIK solution usage during coronary bypass operation of diabetic patients. Methods: Patients with type 1 and 2 diabetes mellitus (DM) referred for coronary artery bypass grafting (CABG) were randomized to receive GIK solution (GIK - study group) in the first 24 hours intraoperatively or to receive official Clinical protocol without GIK solution (non GIK - control group). The primary clinical outcome was the cardiac index (CI) since it represents the most sensitive measure of cardiac work in the immediate postoperative period, and the secondary clinical outcomes were the glycemic control, insulin consumption, duration of mechanical ventilation (MV), potassium level and atrial fibrillation (AF) appearance. Results: One hundred diabetic patients, divided into two groups, were included in the study. The cardiac index did not show a significant difference, although the study group had CI with only minor variations than those of the controlled group, hence the reason we considered the study group as the more stable. The atrial fibrillation showed a difference between two groups, with $14(28 \%)$ patients with postoperative AF in the control group compared with 3 (6\%) patients with postoperative AF in the study group. As potassium values were stable in study group, we concluded that it can be one of the reasons for less postoperative AF in this group. The duration of MV showed a significant difference $(0,003)$ between the two groups as well. In the study group the average MV time was 534,38 minutes, compared with the control group with 749,20 minutes. The average value of glucose was $11.1 \mathrm{mmol} / \mathrm{l}$ in the control group vs. $9.8 \mathrm{mmol} / \mathrm{l}$ in the study group. The study group had less insulin consumption in order to maintain target glycemia $(\mathrm{p}=0,001)$. In the non GIK group average insulin consumption was 44 IJ per patient vs. 28,5 IJ in the GIK group. Conclusion: Intraoperative GIK solution given to diabetic patients with CABG operation provides more stable $\mathrm{CI}$, shorter time of $\mathrm{MV}$, more stable values of potassium which provides normal rhythm and less AF onset, less insulin to maintain target glycemia. All the above mentioned provides more stable intraoperative hemodynamic and better recovery of diabetic patients with coronary artery bypass operations. Key words: diabetes mellitus, coronary artery bypass operation, glucosa-insulin-potassium solution, intraoperative glucose control
\end{abstract}

Corresponding author: Slavenka Straus, MD, Msc. Heart Center, Clinical center of University of Sarajevo. 71000 Sarajevo, Bolnicka 25. Tel.: +387 33297000.

\section{INTRODUCTION}

Diabetes is metabolic disturbance characterized with hyperglycemia which is the risk factor for cardiovascular complications, caused by mi- cro angiopathy and macro angiopathy changes. Diabetes mellitus type 2 is the most frequent form presenting up to $90 \%$ all verified diabetic patients, which presents $3 \%$ to $5 \%$ of total popula- tion. Diabetes mellitus type 2 increases risk of cardiovascular complications by two to four times, and more than 50\% of such patients with diabetes dies from cardiovascular diseases.

Diabetic heart disease includes coronary artery disease, heart failure and diabetic cardiomyopathy. In diabetics, coronary artery disease has a higher prevalence compared to non-diabetics, more expensive treatment, the disease is multiple vessel disease and has a rapid progression.

In diabetic populations with severe coronary artery disease, coronary artery bypass surgery (CABG) is associated with an increased rate of intraoperative complications compared with non-diabetics. Postoperative myocardial dysfunction is exacerbated by the presence of diabetes, so cardiac low output syndrome is more common in the postoperative period in diabetics. It also increased the rate of re-hospitalization and additional treatment. In cardiac surgery there are three factors involved in the occurrence of stress reactions-surgical induced stress, anesthetic-induced stress and the stress that causes the use of cardiopulmonary bypass (CPB). The hyperglycemia is the result of all mentioned stress reaction and in this way caused hyperglycemia can induce heart damage in different ways.

GIK solution limits post ischemic tissue necrosis, infarction and acidosis, and prevents myocardial stunning. 
This results in improving $\mathrm{CI}$, shorter period of $\mathrm{MV}$, reduction in postoperative rhythm disturbances, better energy balance of muscles and endothelial function improvement. All mentioned above, results in better myocardial function and left ventricle contractility.

\section{AIM OF STUDY}

Aim of this study was to confirm the benefits of intraoperative GIK solution usage during coronary artery bypass operation of diabetic patients.

\section{PATIENTS AND METHODS}

Patients were divided into two groups (GIK group-study and non GIK group-control), each with 50 diabetics scheduled for CABG; one group received itraoperatively GIK solution and one was operated without GIK solution. All patients were operated in the Heart Centre, Clinical Center of Sarajevo University, in the period from January 2007 to March 2011, the study was prospective. Data were collected from official medical files and specially created questionnaire made for our study.

Inclusion criteria were: verified diabetic patients with indication for CABG, elective double or triple CABG done with $C P B$, patients were in the age range $18-80$ years, both sexes. Criteria for exclusion were: redo surgery, surgery without use of $\mathrm{CPB}$, combined operations (coronary artery bypass with valve replacement or plastic) and emergency cases.

The parameters that were monitored were: intraoperative-use of arterial grafts, aortic crossclamp time and $\mathrm{CPB}$ time; postoperative-time of mechanical ventilation, occurrence of intraoperative infarction, rhythm disorder, kidney dysfunction, multiple organ failure, stroke, use of blood and blood products; hemodynamics - cardiac index; laboratory parameters glucose and quantity of used insulin to maintain target glycemia. The cardiac index values were measured using a Swan-Ganz catheter. All collected data were recorded immediately after admission of patients in the intensive care unit, 6, 12 and 24 hours after the operation. We used the "soft" control of blood glucose level, which implied glycemia in values between 6 and $10 \mathrm{mmol} / 1$.

Statistic is presented by $X^{2}$ test, Fisher's test, Kolmogorov Smirnov test, parametric tests (student-test and ANOVA test), nonparametric tests (Mann-Whitney U test, Kruskal-Wallis test). For statistic analysis SPSS FOR Windows was used (version 20.0, SPSS Inc, Chicago, Illinois, USA) and Microsoft Excel (version 2010, Microsoft Corporation, Redmond, WA, USA). Level of significancy was $\mathrm{p}<0.05$.

\section{RESULTS}

All relevant patients preoperative data and operative data are shown in the Table 1 and Table 2.

We found the cardiac index $(\mathrm{CI})$ as the primary marker, since it represents the most sensitive measure of cardiac work in the immediate postoperative period. We did not get a significant difference in cardiac index of the observed groups, although the study group had cardiac index with only minor variations than those of the controlled group. As the study group had less variations in CI, we considered it as the more stable group

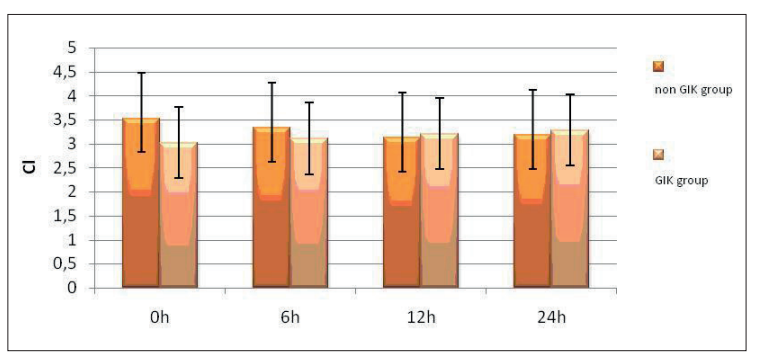

Chart 1. Cardiac index values in both groups

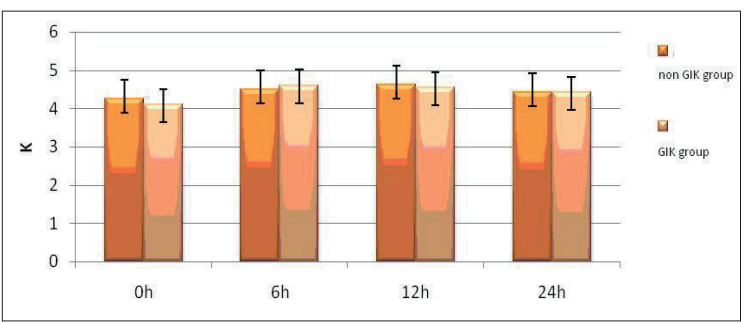

Chart 2. Potassium minimal, maximal and mean values

\begin{tabular}{|l|l|l|} 
& GlK group & non GIK group \\
\hline Age (y) & $62.50+-7.96$ & $61.08+-7.04$ \\
\hline Gender (M/F) & $35 \mathrm{M} / 15 \mathrm{~F}$ & $29 \mathrm{M} / 21 \mathrm{~F}$ \\
\hline $\mathrm{BMI}$ & $29.11+-4.01$ & $29.44+-3.89$ \\
\hline $\mathrm{EF}$ (average) & $50 \%$ & $45 \%$ \\
\hline Previous stroke (no/\%) & $6(12 \%)$ & $4(8 \%)$ \\
\hline $\begin{array}{l}\text { Previous myocardial } \\
\text { infarction }\end{array}$ & $21(32 \%)$ & $27(54 \%)$ \\
\hline $\begin{array}{l}\text { Atrial hypertension } \\
\text { Peripheral vascular } \\
\text { disease }\end{array}$ & $34(68 \%)$ & $43(86 \%)$ \\
\hline $\begin{array}{l}\text { DM insulin/oral } \\
\text { hypoglycemic(s) }\end{array}$ & $\begin{array}{l}24(48 \%) / 26 \\
(52 \%)\end{array}$ & $\begin{array}{l}21(42 \%) / 29 \\
(58 \%)\end{array}$ \\
\hline
\end{tabular}

Table 1. Patient baseline characteristics

\begin{tabular}{|l|l|l|}
\hline $\begin{array}{l}\text { Cardiopulmonary bypass } \\
\text { (min) average }\end{array}$ & GIK group & non GIK group \\
\hline $\begin{array}{l}\text { Aortic cross-clamp (min) } \\
\text { average }\end{array}$ & $41,5 \mathrm{~min}$ & $77 \mathrm{~min}$ \\
\hline $\begin{array}{l}\text { Reoperation for bleeding } \\
\text { (no/\%) }\end{array}$ & $1(2 \%)$ & $1(2 \%)$ \\
\hline
\end{tabular}

Table 2. Patient operative data

\begin{tabular}{|l|l|l|l|l|} 
& Atrial fibrillation & No & $\%$ & $\begin{array}{l}\text { Cumulative } \\
\%\end{array}$ \\
\hline \multirow{2}{*}{$\begin{array}{l}\text { Non GIK } \\
\text { group }\end{array}$} & No & 36 & 72,0 & 72,0 \\
\cline { 2 - 5 } & Yes & 14 & 28,0 & 100,0 \\
\cline { 2 - 5 } & Total & 50 & 100,0 & \\
\hline \multirow{2}{*}{$\begin{array}{l}\text { GIK } \\
\text { group }\end{array}$} & No & 47 & 94,0 & 94,0 \\
\cline { 2 - 5 } & Yes & 3 & 6,0 & 100,0 \\
\cline { 2 - 5 } & Total & 50 & 100,0 & \\
\hline
\end{tabular}

Table 3. Atrial fibrillation in both groups

due to cardiac index and hemodynamics (Chart 1).

Onset of the atrial fibrillation was present in $14(28 \%)$ patients in the non GIK group compared with 3 (6\%) patients in the GIK group (Table 3).

In the non GIK group there was a statistically significant difference in the measurement of potassium between the 6th and 12th hour $\mathrm{p}=0.049$, and between the 12th and 24th p $=0.014$ hours. In the GIK group there were no statistically significant differences in deviation of repeated measurements of potassium, except during the interval between the measurement 0 and 6 th hour ( $\mathrm{p}<0.005)$, indicating that the GIK group was stable. As potassium values were stable in the GIK group, we concerned that as one of the reasons of less AF onset in this group (Chart 2).

There is also a significant difference $(0,003)$ between the two groups in time on mechanical ventilation. The mean time of MV in non GIK group was 749,20 minutes vs. 534,38 minutes in GIK group (Table 4). 


\begin{tabular}{|l|l|c|c|c|c|c|c|c|c|}
\hline \multirow{2}{*}{ GROUP } & & \multicolumn{9}{|c|}{} & \multicolumn{3}{|c|}{ Percentiles } \\
\cline { 3 - 9 } & & $N$ & Mean & $\begin{array}{c}\text { Std. } \\
\text { Deviation }\end{array}$ & Minimum & $\begin{array}{c}\text { Maxi- } \\
\text { mum }\end{array}$ & $25^{\text {th }}$ & $\begin{array}{c}\text { Median } \\
\left(50^{\text {th }}\right.\end{array}$ & $75^{\text {th }}$ \\
\hline Non GIK & $\begin{array}{l}\text { Mechanical } \\
\text { Ventilation }\end{array}$ & 50 & 749,20 & 348,146 & 360,00 & 1440,00 & 457,50 & 585,0 & 1035,00 \\
\hline GIK & $\begin{array}{l}\text { Mechanical } \\
\text { Ventilation }\end{array}$ & 50 & 534,38 & 216,21 & 1,44 & 1140,00 & 389,75 & 498,50 & 582,00 \\
\hline & & & & & $\mathrm{p}=0.003$ & & & & \\
\hline
\end{tabular}

Table 4. Time of mechanical ventilation (minutes)

\begin{tabular}{|l|l|l|l|l|l|l|l|l|l|}
\hline Insulin & N & Mean & $\begin{array}{l}\text { Std. De- } \\
\text { viation }\end{array}$ & $\begin{array}{l}\text { Mini- } \\
\text { mum }\end{array}$ & $\begin{array}{l}\text { Maxi- } \\
\text { mum }\end{array}$ & 25th & $\begin{array}{l}\text { Percen- } \\
\text { tiles Me- } \\
\text { dian 50th }\end{array}$ & 75 th & $P$ \\
\hline $\begin{array}{l}\text { non GIK } \\
\text { group }\end{array}$ & 50 & 48,30 & 27,48 &, 00 & 135,00 & 28,00 & 44,0 & 66,00 & $p=0.001$ \\
\hline GIK group & 50 & 30,66 & 23,54 &, 00 & 102,00 & 12,00 & 28,5 & 42,00 & \\
\hline
\end{tabular}

Table 5. Total insulin consumption in the first 24 postoperative hours

Bearing in mind how much can be harmful appearance of hyperglycemia in the early postoperative recovery, we observed it in our study. In both groups, there was an increase in blood sugar levels. In the control group the highest value of glycemia was $18.2 \mathrm{mmol} / \mathrm{l}$, vs. $18 \mathrm{mmol} / \mathrm{l}$ in the study group. With the rapid correction of hyperglycemia with an IV. bolus of insulin, desired glycemia values were achieved. The average value of postoperative glycemia was $11.1 \mathrm{mmol} / \mathrm{l}$ in the control group vs. 9.8 $\mathrm{mmol} / \mathrm{l}$ in the study group. (Chart 3).

The insulin consumption in groups were different. In the non GIK group mean value of insulin consumption was $44 \mathrm{IJ}(28 \mathrm{IJ}-66 \mathrm{IJ})$ vs $28,5 \mathrm{IJ}$ (12IJ - 42IJ) in the GIK group. So, the GIK group had less insulin consumption in order to maintain target glycemia $(0,001)$ (Table 5).

There were no significant differences between two observed groups in postoperative kidney insufficiency with indicated hemodialysis, stroke, reinfarction, indication for re-exploration, used blood and blood products and quantity of used inotropes.

\section{DISCUSSION}

During the past few years, it has become evident that the metabolic control is very important for postoperative outcomes for all surgical patients. The current findings suggest that a small increase in blood glucose may jeopardize the patients (diabetics and non diabetics) with cardio surgery operations, gave a significant reduction of AF in GIK group as well as Gandhi GY presented in his study (8). Rabi D and De Barcellos CS studies showed that there was no difference in the occurrence of ventricular and supraventricular arrhythmias between the groups. $(9,4)$ Many authors and their studies suggested a positive effect of the GIK solution usage due to prevention of postoperative rhythm disturbances, especially AF such as Furnary AP, Kirdemir P, Haga KK $(10,11)$.

Normal value of potassium is necessary to preserve the rhythm and thus hemodynamics. Occurrence of either hypokalemia or hyperkalemia, especially in the early postoperative recovery, can lead to fatal complications-hypokalemia to malignant arrhythmias and hyperkalemia to cardiac arrest. In our study, potassium values were stable in GIK group compare with the non GIK group, therefore the study group had less rhythm disturbance and stable hemodynamics. Rabi D and De Barcellos CS studies confirmed the same results as our study (4).

Only 6 studies, of 20 analyzed, yielded data on the potassium trend, and from 6 studies, only one provided data on hyperkalemia appearance (12).

According to the currently presented data, it is unclear what should be the "ideal" glycemia control in diabetic patients with a cardiac bypass surgery? Diabetic patients have increased morbidity and mortality after CABG. Surgical, anesthetic studies and studies on patients treated in intensive care units, testify in favor of well-controlled glycemia. This is especially important for diabetics who than have better postoperative recovery (13). In our study, we used arterial blood to measure glycemia. Guided by previous published studies, works and published meta-analysis, we decided to use not strict glycemic control $(6.5-10 \mathrm{mmol} / \mathrm{l})$. In our study we found statistically significant difference in insulin consumption between groups (p 0.001) in order to achieve desired glycemia. Insulin is more used in the non GIK group.

Prior to the year 2001, due to the lack of data about the benefits of strict glycemic control, not enough attention was paid to the existence of hyperglyce- 
mia in the intensive care unit. Then, a lot of studies about this topic were published, Van den Berghe G 2001, 2006 and 2009, Arabi YM, 2008, Brunkhort FM 2008, De la Rosa GDC 2008, Preiser JC $2009(14,15)$. The conclusions of the following studies: SICU and MICU van den Berghe G, DIGAMI, CREATEECLA, DIGAMI 2, GIS, VISEP, Glucontrol Study, NICE-SUGAR, consider the current acceptance of universal guides or recommendations on the desired normoglycemia premature. They propose that each unit of intensive care defines their own framework for glycemic therapy and that this process should be crated due to existing economic and organizational resources (16). Standardization is something that is mandatory. The desired glycemia must be based on data and realistic for each individual institution. Requires constant monitoring of outcomes and success in achieving the desired glycemia, and continuing education of health care workers and correction protocols. Some of the protocols are efficient, but still so far there are no published randomized clinical studies that prove "the best protocol" $(17,18)$.

Since it is not exactly determined the optimal glycemia and the exact protocol, it is advisable to stick to the old postulates "first, do no harm" (19).

\section{CONCLUSION}

Intraoperative GIK solution given to diabetic patients with CABG gives more stable $\mathrm{CI}$, shorter time of $\mathrm{MV}$, more stable values of potassium which provides normal heart rhythm, less AF onset, and less additional insulin consumption in order to achieve desirable glycemia. All mentioned above provides more stable intraoperative hemodynamic and better recovery of diabetic patients after coronary artery bypass operation.

\section{REFERENCES}

1. Fan Y, Zhang AM, Xiao YB, Weng YG, Hetzer R. Glucose-insulin-potassium therapy in adult patients undergoing cardiac surgery: a meta-analysis. Euro J Cardiothorac Surg. 2011; 40: 192-199.

2. Howell NJ, Ashrafian H, Drury NE, Ranasinghe $\mathrm{AM}$, Contractor $\mathrm{H}$, Isackson $\mathrm{H}$, et al. Glucose-insulin-potassium reduces the incidence of low cardiac output episodes after aortic valve replacement for aortic stenosis in patients with left ventricular hypertrophy: results from the hypertrophy, insulin, glucose and electrolytes (HINGE) trial. Circulation. 2011; 123: 170-177.

3. Quinn DW, Pagano D, Bonser RS, Rooney SJ, Graham TR, Wilson IC, et al. Improved myocardial protection during coronary artery surgery with glucoseinsulin-potassium: a randomized controlled trial. J Thorac Cardiovasc Surg. 2006; 131: 34-43.

4. De Barcellos CS, Wender OCB, Cerati de Azambuja P. Clinical and hemodynamic outcome following coronary artery bypass surgery in diabetic patients using glucose-insulin-potassium (GIK) solutin: a randomized clinical trial. Rev Bras Cir Cardiovasc. 2007; 22: 275-284.

5. Gandgi GY, Nuttall GA, Abel MD, Mullany CJ, Schaff HV, Williams BA, et al. Intraoperative hyperglycemia and intraoperative outcome in cardiac surgery patients. Mayo Clin Proc. 2005; 80:862-866.

6. Hermans G, Wilmer A, Meersseman W, Milants I, Wouters PJ, Bobbaers H, et al. Impact of intensive insulin therapy on neuromuscular complications and ventilator dependency in the medical intensive care unit. Am J Respir Crit Care Med. 2007;.175:.480-489.

7. The NICE-SUGAR Study Investigators. Finfer S, Chittock DR, Su SY, Blair $\mathrm{D}$, Foster D, Dhingra V, et al. intensive versus conventional glucose control in critically ill patients. N Engl J Med. 2009;.360:.1283-1297.

8. Gandhi GY, Nuttall GA, Abel MD, Mullany CJ, Schaff HV, O'Brien PC, et al. Intensive intraoperative insulin therapy versus conventional glucose management during cardiac surgery. Ann Inter Med. 2007;.146:.233-243.

9. Rabi D, Clement FM, McAlister FA, Majumdar SR, Sauve R, Johnson J, et al. Effect of intraoperative glucose-insulinpotassium infusion on mortality and atrial fibrillation after coronary artery bypass grafting: A systemic review and meta-analysis. Can J Cardio. 2010; 26: e178-e184.

10. Kirdemir P, Yildirim V, Kiris I, Gulmen S, Kuralay E, Ibrisim E, et al. Does continous insulin therapy reduce postoperative supraventricular tachycardia incidence after coronary artery bypass operations in diabetic patients? JCVA. 2008; 22: 383-387.

11. Haga KK, McClymont KL, Clarke S, Grounds RS, Ng KY, Glyde DW, et al. The effect of tight glycemic control, during and after cardiac surgery, on patient mortality and morbidity: A systematic review and meta-analysis. J Cardiothorac Surg. 2011; 6: 3-11.

12. Rabi D, Clement FM, McAlister FA, Majumdar SR, Sauve R, Johnson J, et al. Effect of intraoperative glucose-insulinpotassium infusion on mortality and atrial fibrillation after coronary artery bypass grafting: A systemic review and meta-analysis. Can J Cardio. 2010; 26: e178-e184.

13. Inzucchi S, Kosiborod M. Continous glucose monitoring during critical care. Anesthesiology. 2011; 114: 18-20

14. Van den Berghe G, Schetz M, Vlasselaers D, Hermans G, Wilmer A, Bouillon $\mathrm{R}$, et al. Clinical review: Intensive insulin therapy in critically ill patients: NICE-SUGAR or Leuven blood glucose target? J Clin Endocrinol Metab. 2009; 94: 3163-3170.

15. Preiser JC, Devos P, Ruiz-Santana S, Metol C, Annane D, Gueneveld J, et al. A prospective randomized multi-centre controlled trial on tight glucose control by intensive insulin therapy in adult intensive care units: the Glucontrol study. Intensive Care Med. 2009; 35: 1738-1748.

16. Merz TM, Finfer S. Intensive insulin treatment. Minerva Anestesiol. 2009; 75: 703-709.

17. Székely A, Levin I, Miao Y, Tudor IC, Vuylsteke A, Ofner P, Mangano DT; Investigators of the Multicenter Study of Intraoperative Ischemia Research Group and the Ischemia Research and Education Foundation the intraoperative endocrine stress response was attenuated in patients supplemented with continuous remifentanil infusion as compared to intermittent fentanyl Impact of hyperglycemia on intraoperative mortality after coronary artery bypass graft surgery. L Thorac Cardiovasc Surg. 2011; 142: 430-437.

18. Lazar HL, McDonnell MM, Chipkin S, Fitzgerald C, Bliss C, Cabral H. Effects of aggressive versus moderate glycemic control on clinical outcomes in diabetic coronary artery bypass graft patients. Ann Surg. 2011; 254: 458-463

19. Egi M, Finfer S, Bellomo R. Glycemic control in the ICU. Chest. 2011; 140: 212-220. 